\title{
The nitrogen effect on the oxidation behaviour of Ti6242S titanium-based alloy : contribution of atom probe tomography
}

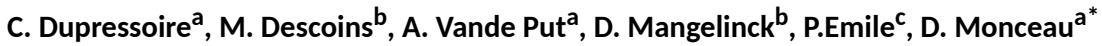

\begin{abstract}
${ }^{a}$ CIRIMAT laboratory, University of Toulouse, CNRS, INPT, UPS, ENSIACET 4 allée Emile Monso, BP-44362, 31030 Toulouse Cedex 4 , FRANCE
\end{abstract}

\author{
bAix-Marseille Université, CNRS, IM2NP, Faculté de Saint-Jérôme, Case 142, 13397 Marseille Cedex 20, FRANCE
}

${ }^{\text {c }}$ Airbus Operations SAS, 316 Route de Bayonne, 31060 Toulouse Cedex 09, FRANCE

*Daniel.Monceau@ensiacet.fr

\begin{abstract}
At high temperatures under oxidizing environments, titanium-based alloys form an oxide scale and dissolve large amount of oxygen in their metallic matrix. Oxygen dissolution is a cause of embrittlement. Nitrogen is a secondary oxidant, which also dissolves in titanium during oxidation in air. Oxidation experiments of Ti-6Al-2Sn-4Zr-2Mo-0.1Si titanium-based alloy at $650{ }^{\circ} \mathrm{C}$ for $1000 \mathrm{~h}$ in synthetic air $\left(20 \% \mathrm{O}_{2}^{-}\right.$ $80 \% \mathrm{~N}_{2}$ ) and in a mixture of $20 \% \mathrm{O}_{2}-80 \% \mathrm{Ar}$, showed that nitrogen reduces both oxide scale growth and oxygen dissolution. Atom probe tomography revealed that nitrogen effect is due to the formation of an interfacial layer of nitride $\mathrm{Ti}_{2} \mathrm{~N}$ but also to the formation of a nitrogen rich a-Ti-based solid solution, which both act as diffusion barriers for oxygen because of their low oxygen solubility.
\end{abstract}

Keywords: Titanium-based alloy, Oxidation, Oxygen dissolution, Nitrogen, Atom probe tomography

\section{Introduction}

For several years, the use of titanium-based alloys has been in full expansion in aircraft industry due to their high specific strength at low or moderate temperatures $\left(<500^{\circ} \mathrm{C}\right)$. However, in-service temperatures have increased leading to more severe oxidation conditions. In addition to oxide scale growth, oxygen dissolution within titanium-based alloys takes place, leading to a loss of ductility [1,2], which can be detrimental to fatigue resistance [3]. Moreover, working environments are also composed of nitrogen and pure titanium can dissolve this element up to 23 at.\%. Nitrogen is known to decrease oxidation kinetics of titanium and its alloys [4, 5]. A previous study [5] on Ti6242S industrial alloy exposed to synthetic air $\left(\mathrm{N}_{2}-20 \% \mathrm{O}_{2}\right)$ and to a gas mixture of $\mathrm{Ar}-20 \% \mathrm{O}_{2}$ at $650{ }^{\circ} \mathrm{C}$ for $100 \mathrm{~h}$ showed that a nitrogen rich environment lead to a thinner and more compact oxide scale. This was accompanied by a lower content in oxygen in the metal at the oxidealloy interface (measured by EPMA) and by a lower overall oxygen dissolution within the alloy. Chaze and Coddet proposed three hypotheses to explain the influence of nitrogen on the oxidation of titanium and $\mathrm{Ti}-\mathrm{X}$ alloys $(\mathrm{X}=\mathrm{Al}, \mathrm{Cr}, \mathrm{Si})[4]$. An oxide $\mathrm{scale}$ of $\mathrm{TiO}_{2}$ is formed on the surface of the metal because titanium oxides are more stable thermodynamically than nitrides. But nitrogen would be incorporated in solution in the rutile layer. As nitrogen diffuses faster in rutile than in titanium [6,7], it should accumulate in the oxide next to the oxide-metal interface [4]. Chaze and Coddet propose that nitrogen could decrease the anionic vacancies concentration in the oxide and then could decrease the driving force for oxygen transport in the rutile scale. The second hypothesis was that oxygen concentration in the metal at the oxide-metal interface, i.e. the oxygen solubility limit in the metal, could be decreased by nitrogen dissolution within the metal. Consequently, this would decrease the inward oxygen flux towards the metal bulk $[4,8]$. The third proposed explanation was to consider that a nitride can form at the oxide-metal interface, as the oxygen partial pressure is low enough to stabilize it at this interface. The formation of such a protective inner nitride layer was reported for binary alloys such as $\mathrm{Ti}-\mathrm{Cr}$ and Ti-Si alloys for which it was claimed that chromium and titanium nitrides were detected by X-Ray Diffraction (XRD) respectively, but no XRD diagram was given by authors [9, 10]. However, nitrides were observed thanks to optical microscopy as a thin gold layer in $\mathrm{Ti}_{3} \mathrm{Al}$ [11] and this is often reported during TiAl oxidation, e.g. [12]. Recently, the formation of a $\mathrm{Ti}_{2} \mathrm{~N}$ nitride was detected by XRD after $5 \mathrm{~h}$ oxidation in air at $700^{\circ} \mathrm{C}$ of shot peening $\mathrm{Ti} \mathrm{CP}$ grade 1 samples. Nuclear reaction analysis (NRA) of these samples revealed a continuous $N$ enrichment below the oxide scale [13]. No other study was found in the literature to explain the nitrogen effect on the oxidation behaviour of $\alpha$ or $\alpha-\beta$ titanium-based alloys. No characterization was found with sufficient spatial and chemical resolutions to quantify the levels of $\mathrm{N}$ and $\mathrm{O}$ in the enriched layers.

To understand the nitrogen effect on oxidation kinetics, it is necessary to measure the nitrogen and oxygen dissolutions at the oxide-alloy interface, and to observe the phase transformations these elements can induce. As conventional methods such as micro-hardness or electron probe microanalyses (EPMA) do not have sufficient spatial and chemical resolutions, atom probe tomography (APT) was tested as a possible mean to get a chemical analysis at the atomic scale. This technique has already been used for a sintered TA6V titanium alloy to understand the loss of ductility observed experimentally when an oxygen concentration of 0.33 at.\% is reached [14]. Another work studied the chemical composition of phases for a TA6V alloy produced by electron beam melting (EBM) 3D-printing, in order to explain the decrease in its tensile strength [15]. Rug et al. tested several high resolution technics including atom probe [16]. They showed that it was possible to measure the composition of a Ti-6Al-4V alloy containing $0.4 \mathrm{wt} \% \mathrm{O}$. They could also measure $\mathrm{O}$ (about $1 \mathrm{wt} \%$, detected as TiO) and $\mathrm{N}$ enrichment (about $0.4 \mathrm{wt} \%$ ) 1-2 $\mu \mathrm{m}$ below a slightly oxidized surface.

However, APT has never been used to characterize the oxide-alloy interface of the titanium-based alloys, with $\mathrm{O}$ and $\mathrm{N}$ dissolutions in the metal which could reach up to 33 at\% and 23 at\% respectively. Indeed, this analysis may appear difficult as this interface is expected to be 
insulating and very brittle. In this work, we report a successful APT analysis of the oxide-alloy interface. The distribution of chemical elements was studied at the oxide-alloy interface and in the zone just below it to understand the role of nitrogen on the oxidation of Ti6242S alloy.

\section{Experimental}

The material used in this study was the Ti6242S titanium-based alloy. It was forged by Aubert and Duval (Pamiers, France). Table 1 summarizes its chemical composition determined by energy dispersive X-ray spectroscopy (EDX) for major elements and instrumental gas analyses (IGA) for gas-forming elements (detection limits (wt.\%): $0.5 \mathrm{ppm}$ for hydrogen, $5 \mathrm{ppm}$ for carbon, nitrogen and sulphur, $10 \mathrm{ppm}$ for oxygen) by Evans Analytical Group (Tournefeuille, France). Observation by scanning electron microscopy (SEM) of Ti6242S was performed after etching in Kroll's solution (1.4 vol.\%, 2.5 vol.\%, bal. $\mathrm{H}_{2} \mathrm{O}$ ) using the backscattered electron (BSE) mode. It revealed a duplex microstructure, which consisted of lamellar and globular a phase (light in SEM-BSE image) in a thin $\beta$ phase (dark in SEM-BSE image) (Figure 1).

Table 1: Chemical composition of Ti6242S alloy

\begin{tabular}{|c|c|c|c|c|c|c|c|c|c|c|c|c|}
\hline Element & Ti & Al & Sn & Zr & Mo & Si & O & N & C & S & H \\
\hline & \multicolumn{9}{|c|}{$\%$} \\
\hline In weight & Bal. & 6.0 & 1.8 & 4.0 & 2.1 & 0.1 & 1200 & $<5$ & 26 & 8.2 & 44 \\
\hline In atoms & Bal. & 10.5 & 0.7 & 2.1 & 1.0 & 0.2 & 3550 & $<17$ & 103 & 12 & 2062 \\
\hline
\end{tabular}

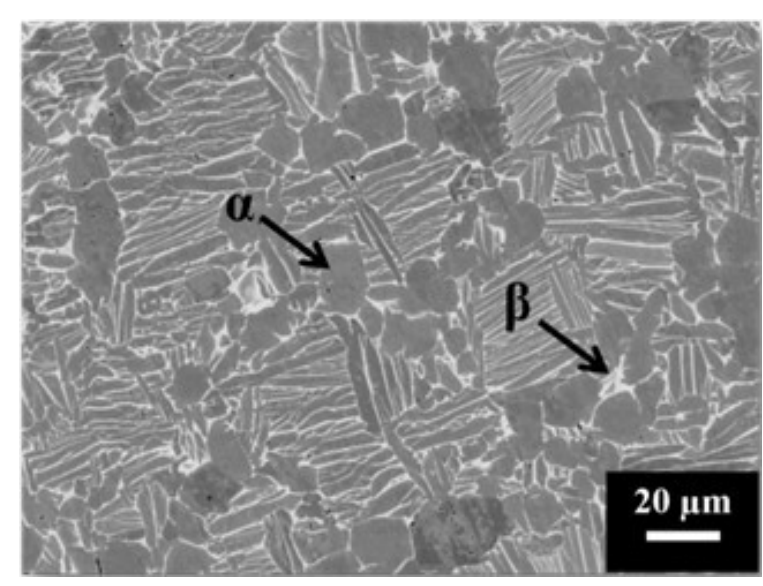

Figure 1: SEM observation of Ti6242S microstructure (BSE mode)

Samples used were thin plates of $15 \times 10 \times 1 \mathrm{~mm}^{3}$ ground before oxidation using P240 SiC grinding paper. Then, they were cleaned with

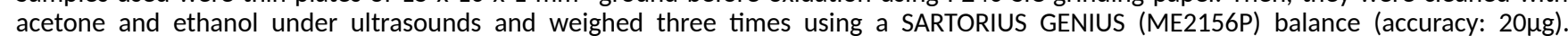
Oxidation treatments performed in a thermobalance for $100 \mathrm{~h}$ at $650{ }^{\circ} \mathrm{C}$ in synthetic air and in $\mathrm{Ar}-20 \% \mathrm{O}_{2}$ were prolonged to $1000 \mathrm{~h}$ in an oxidation bench with the same conditions of temperature and atmosphere. The flux of gaz was $8.5 \mathrm{ml} / \mathrm{min}$ corresponding to a gas velocity of $4.5 \times 10^{-4} \mathrm{~m} / \mathrm{s}$ for tests in thermobalance. For long-term oxidations, the flux of gas was $100 \mathrm{ml} / \mathrm{min}$ and $51 \mathrm{ml} / \mathrm{min}$ which was equivalent to $2.5 \times 10^{-4} \mathrm{~m} / \mathrm{s}$ and $1.2 \times 10^{-4} \mathrm{~m} / \mathrm{s}$ for synthetic air and $\mathrm{Ar}-20 \% \mathrm{O}_{2}$ respectively. Mass variations were measured three times after several exposure durations using the SARTORIUS GENIUS balance.

Characterization of the oxide-alloy interface was performed thanks to APT at IM2NP (Marseille, France). Before analyses, specimens were prepared by focused ion beam (FIB) on a FEI HELIOS 600i dual beam using lift-out technique at IM2NP [17]. The micro-tips were obtained by following the annular milling method [18] in order to have an end radius of about $100 \mathrm{~nm}$. APT analyses were carried out with a LEAP 3000x $\mathrm{HR}$ at a temperature of $40 \mathrm{~K}$, using a $100 \mathrm{kHz}$ picosecond laser pulse with an energy between 0.5 and $1.2 \mathrm{~nJ}$. IVAS 3.6.2 software was chosen to reconstruct data. Three specimens per atmosphere were successfully analysed.

\section{Results and discussion}

\section{Oxidation behaviour}

The mass variations obtained in synthetic air after $1000 \mathrm{~h}$ at $650{ }^{\circ} \mathrm{C}$ were about 2.3 times lower than those in $\mathrm{Ar}-20 \% \mathrm{O}_{2}(\mathrm{Figure} 2)$. This confirms our previous observations after $100 \mathrm{~h}$ exposure (5). The oxide scale formed in $\mathrm{Ar}-20 \% \mathrm{O}_{2}$ is much thicker than the oxide scale formed in air (not shown here). The oxide scale formed in $\mathrm{Ar}-20 \% \mathrm{O}_{2}$ is layered, whereas it is not when oxidation is performed in air. An important point is that oxygen concentration in the metal at the oxide-alloy interface, measured by EPMA, was 2 to 3 times higher in the Ar$20 \% \mathrm{O}_{2}$ gas mixture than in synthetic air (Figure 3), a few micrometers away from the interface. 
From these analyses, the mass gain associated to oxygen dissolution was calculated from the integrated surface area below the 0 concentration profiles. The mass gain associated with the oxide scale was deduced from the difference between the total mass gain and the one related to dissolution. To check the calculations, the mass gain due to the external scale growth was also estimated from its thickness. As in our previous study [5], $1000 \mathrm{~h}$ oxidation tests confirm that the mass gains associated to these two phenomena are both higher in Ar$20 \% \mathrm{O}_{2}$ than in synthetic air (Figure 4).

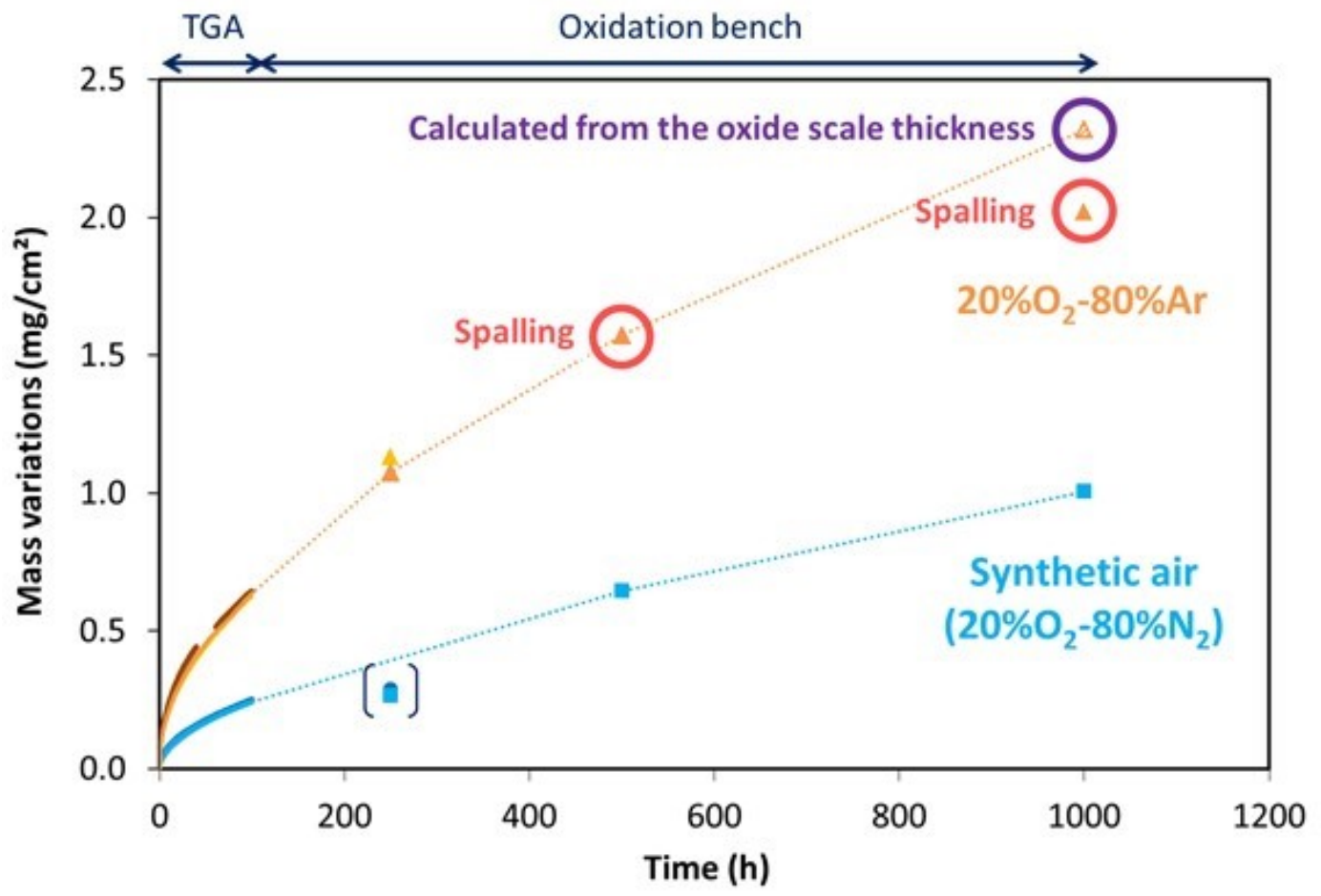

Figure 2: Mass variation vs time for Ti6242S alloy oxidized at $650^{\circ} \mathrm{C}$ in flowing synthetic air and Ar- $20 \% \mathrm{O}_{2}$ gas mixture

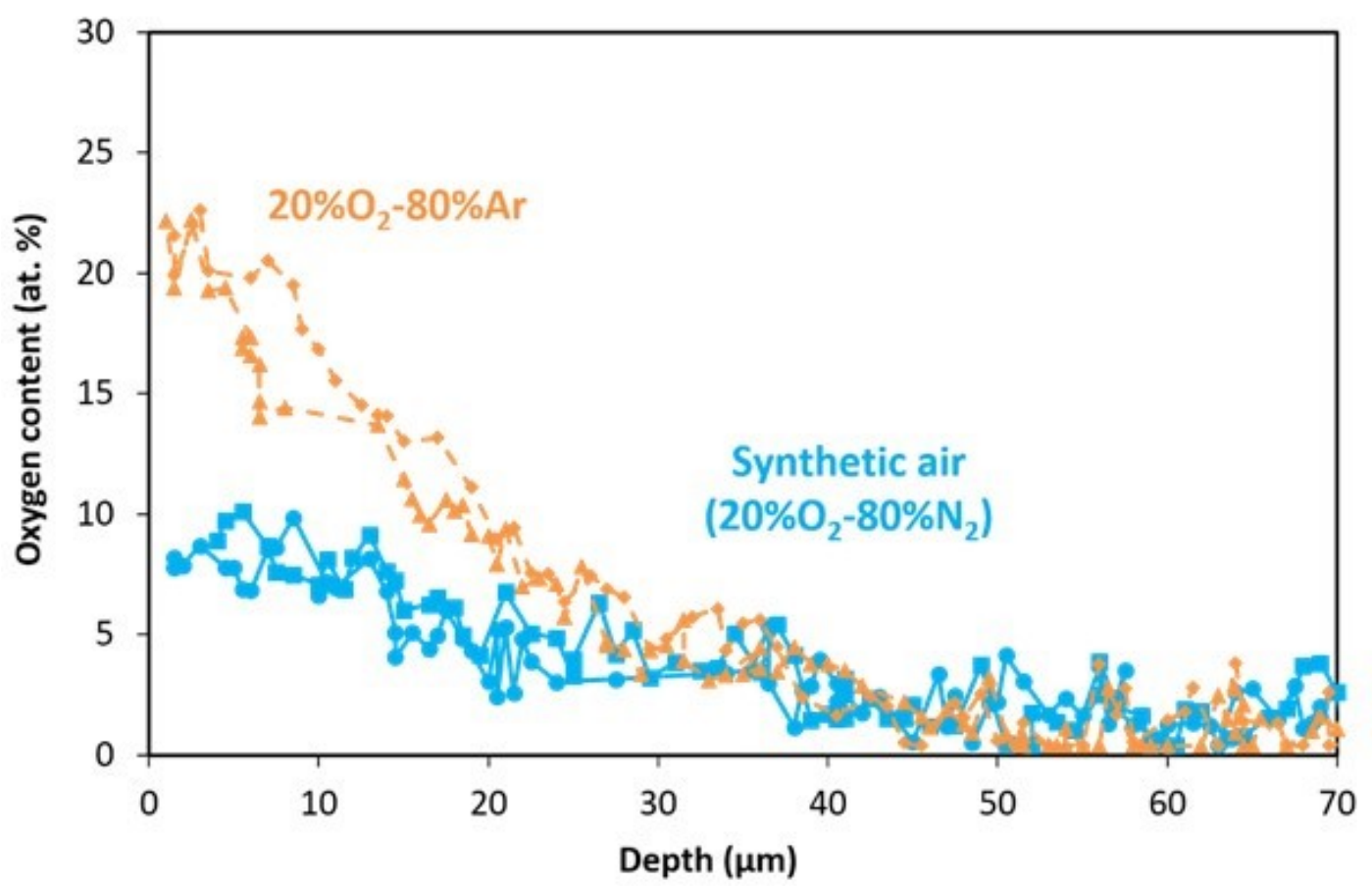

Figure 3: EPMA profiles for oxygen for Ti6242S oxidized at $650{ }^{\circ} \mathrm{C}$ for $1000 \mathrm{~h}$ in synthetic air (squares, circles and continuous lines) and $20 \% \mathrm{O}_{2}-80 \% \mathrm{Ar}$ (triangles, diamonds and dashed lines) 


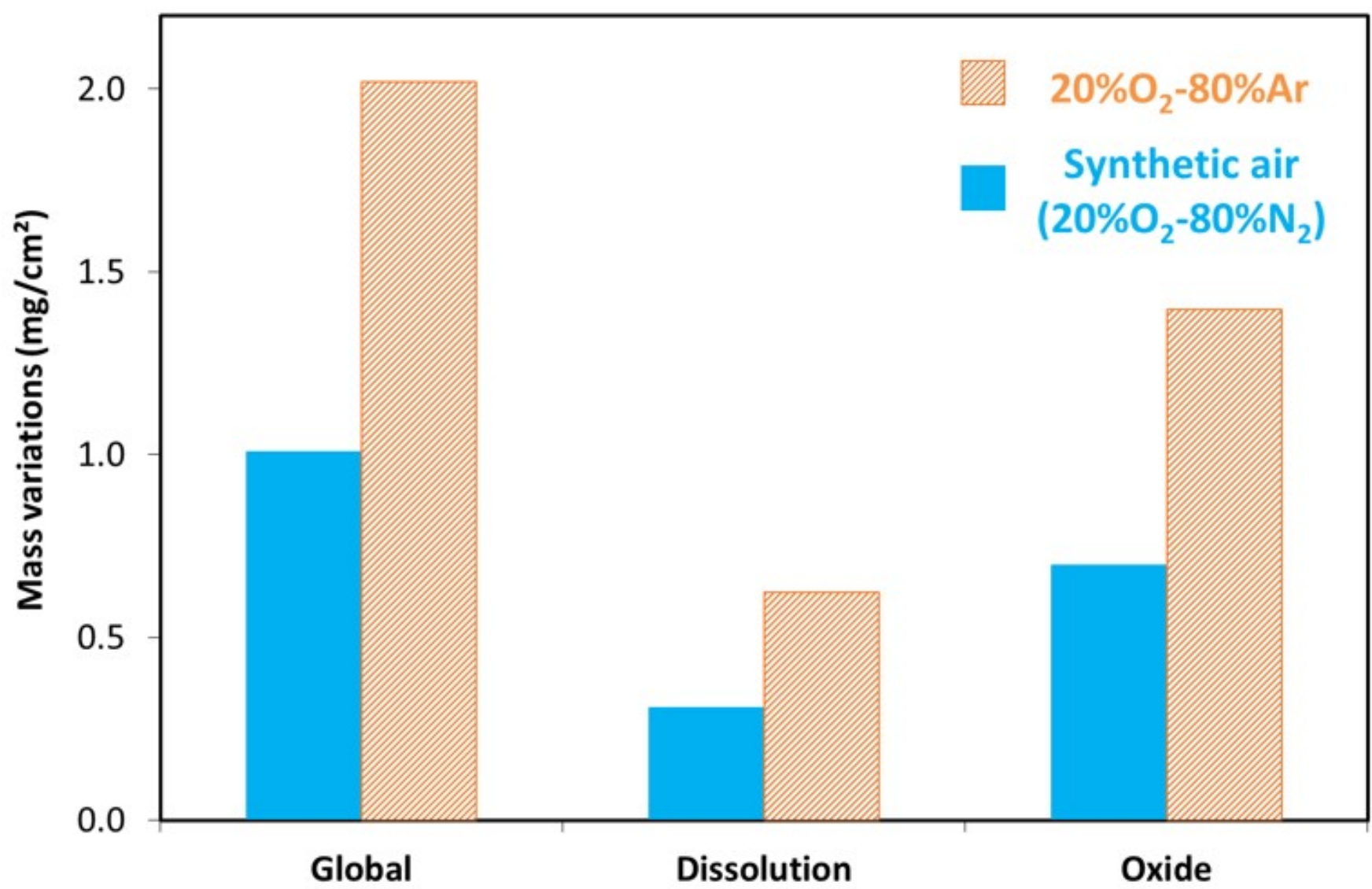

Figure 4: Mass variations associated to global oxidation kinetics, to oxygen dissolution in the alloy calculated from EPMA analyses and to oxide scale growth calculated by difference for Ti6242S alloy oxidized at $650{ }^{\circ} \mathrm{C}$ for $1000 \mathrm{~h}$ in flowing synthetic air and $\mathrm{Ar}-20 \% \mathrm{O}_{2}$ gas mixture.

APT analyses were then performed on three micro-tips for each atmosphere. The results obtained were similar for a given atmosphere, therefore only one specimen for the $\mathrm{Ar}-20 \% \mathrm{O}_{2}$ environment and two specimens for synthetic air are presented in this paper (Figure 5).
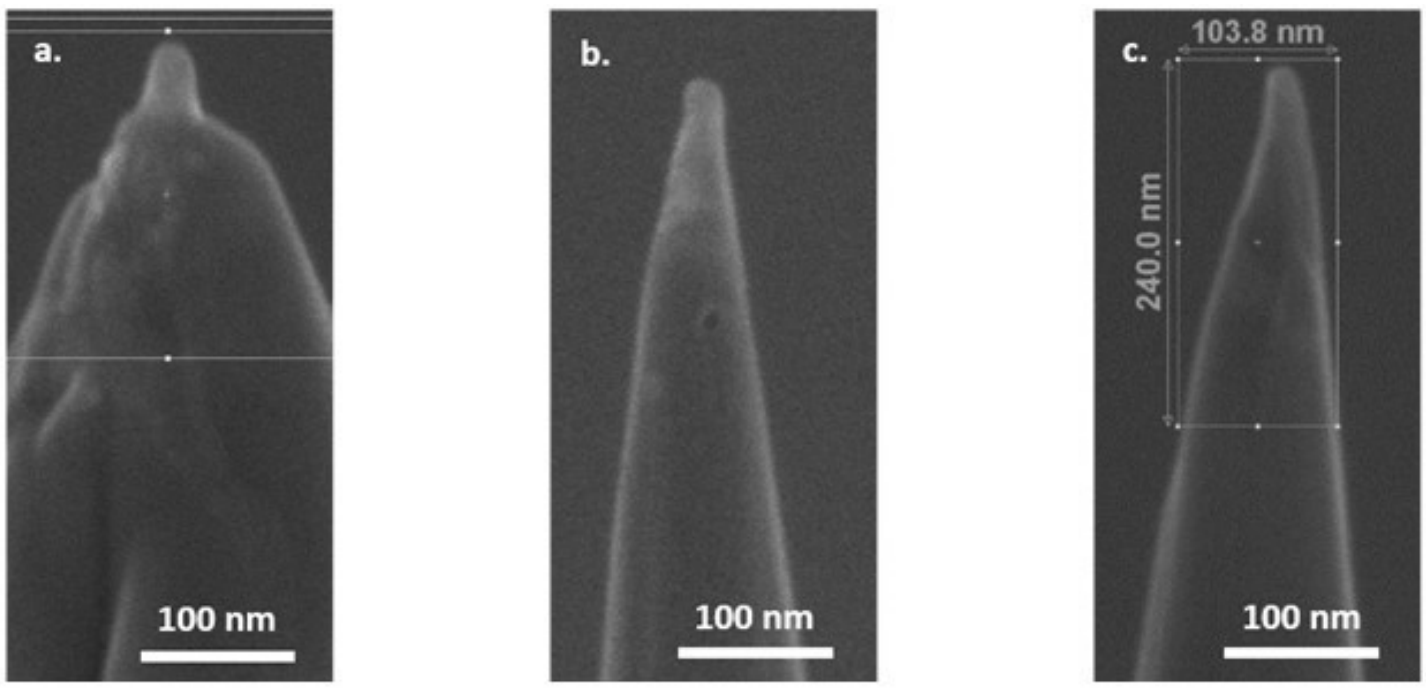

Figure 5: SEM-FEG (Secondary Electron mode) observations of micro-tips obtained by FIB and analysed by APT for Ti6242S oxidized $1000 \mathrm{~h}$ at $650{ }^{\circ} \mathrm{C}$ in a. $\mathrm{Ar}-20 \% \mathrm{O}_{2}$, b. and c. synthetic air 
Concentration profiles were calculated from the APT data along cylinders taken perpendicular to the metal/oxide interface (Figure 6, Figure 7, Figure 9).

Two zones were observed in the micro-tips related to the $\mathrm{Ar}-20 \% \mathrm{O}_{2}$ exposure (Figure 6). The first one, zone A, corresponds to the oxide scale close to the metal/oxide interface. It was rich in titanium and oxygen with about 50at\%O. Two sub-zones could be observed: zones $\mathrm{A} 1$ and A2. Comparing with the Ti-O phase diagram, this could correspond to the two following oxides: stoichiometric a-TiO (50 at\% O) and defective $\mathrm{a}-\mathrm{T}_{1-\mathrm{x}} \mathrm{O}(54 \mathrm{at} \% \mathrm{O})$. The concentrations in O measured in zones $\mathrm{A} 1$ and $\mathrm{A} 2$ were resp. 49 at $\%$ and 40 at $\%$, i.e. 10 to $25 \%$ of $\mathrm{O}$ could be missing in the analysis. This deficit in O is often observed in APT [19]. The second one (zone B) was mainly composed of titanium, oxygen and aluminium. The oxygen content (29 at.\%) was slightly below its theoretical solubility limit of 33 at.\% in pure titanium. Once again, this corresponds to $13 \%$ of O missing in the analysis. The aluminium concentration in zone B was about 8 at.\% which is close to, but lower than the one of the alloy. Because of this concentration in $\mathrm{O}$ and $\mathrm{Al}$, and the fact that only little b-Ti gene element Mo is detected, this phase should be the $a-T i$ phase saturated in oxygen, noted $a-T i(O)$ in this paper.

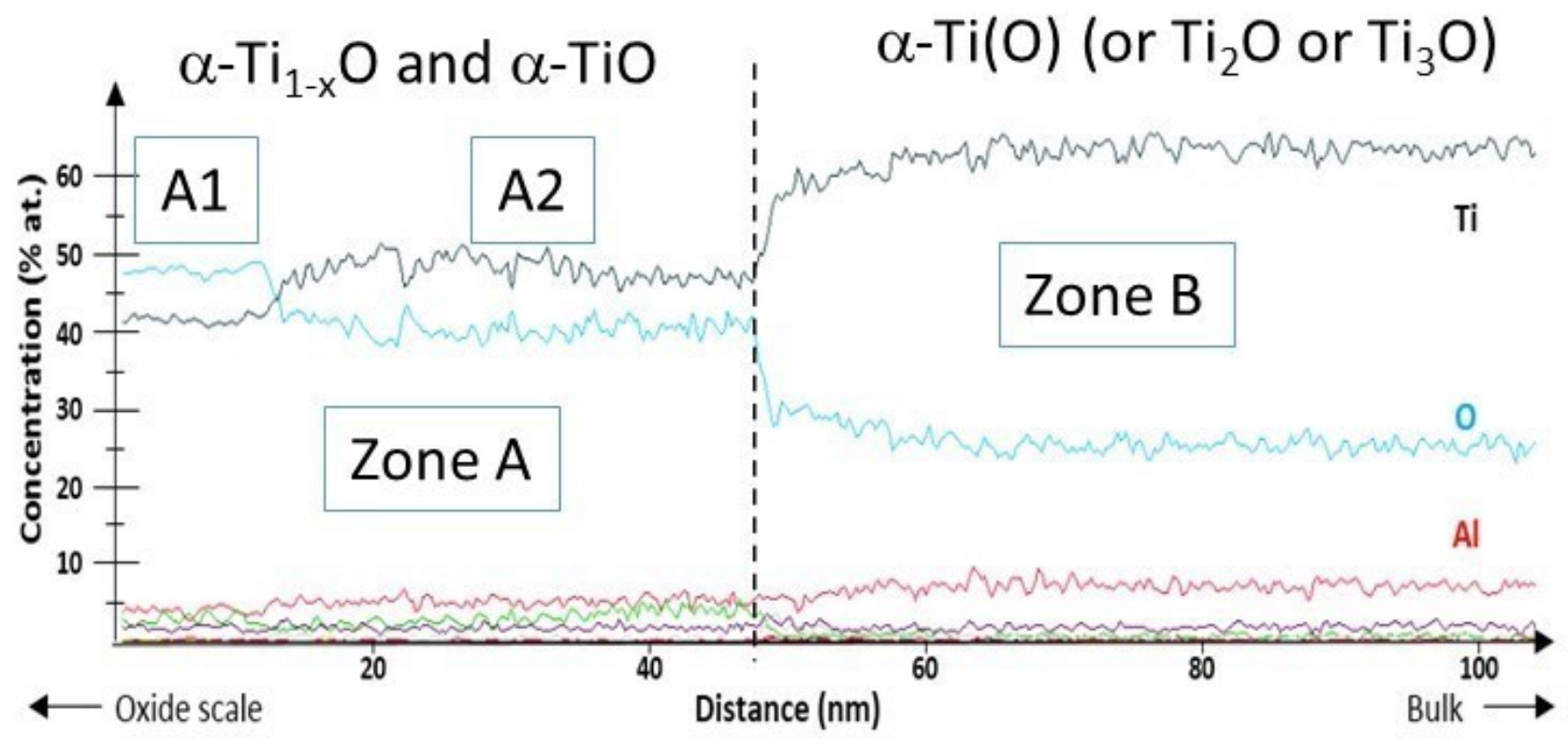

Figure 6: Concentration profiles in one micro-tip analysed by APT after oxidation at $650{ }^{\circ} \mathrm{C}$ for $1000 \mathrm{~h}$ in $\mathrm{Ar}-20 \% \mathrm{O}_{2}$

For the sample oxidized in synthetic air, concentration profiles obtained in the longitudinal direction are shown in Figure 7. On the extreme surface, which corresponds to the inner part of the oxide scale, high concentrations of oxygen, nitrogen and titanium were measured, suggesting an oxinitride phase (zone C). No definitive proof of the presence of an oxinitride can be given because of the compositional gradient over a few nanometres. Below this, another zone enriched in titanium and nitrogen and containing some oxygen was observed (zone D). As the titanium to nitrogen ratio was equal to 1.6 and because an aluminium depletion was noticed in this area (Al solubility in $\mathrm{Ti}_{2} \mathrm{~N}$ nitride is close to zero [20]), this area could correspond to a $\mathrm{Ti}_{2} \mathrm{~N}$ nitride layer, $20 \mathrm{~nm}$ thick. A third zone was composed of titanium, nitrogen and also aluminium. As the aluminium content was close to the one of the alloy (slightly more than 10 at\%) with very little Mo, this should be the a-Ti phase containing a great amount of nitrogen (up to 23 at.\%). This latest value is large for the $a$-Ti phase which should dissolved about 6 at $\%$ at $650^{\circ} \mathrm{C}$ but can dissolved up to 23 at $\%$ in pure $a-T i$ at $1050^{\circ} \mathrm{C}$ [21]). Finally, Figure 7 reveals that $a-T i(N)$, saturated in nitrogen, dissolved only 1 at.\% of oxygen 20 or $30 \mathrm{~nm}$ below the oxide scale, whereas O concentration is about 10at\% after oxidation in air, a few micrometers below the oxide scale, as seen in Figure 3. This is a very interesting observation, which shows that oxygen is rejected from the metal below the oxide scale when this one contains large amounts of nitrogen. The growth of the very thin nitride and/or $\mathrm{N}$ saturated a-Ti(N) layers reject oxygen deeper in the metallic alloy. 


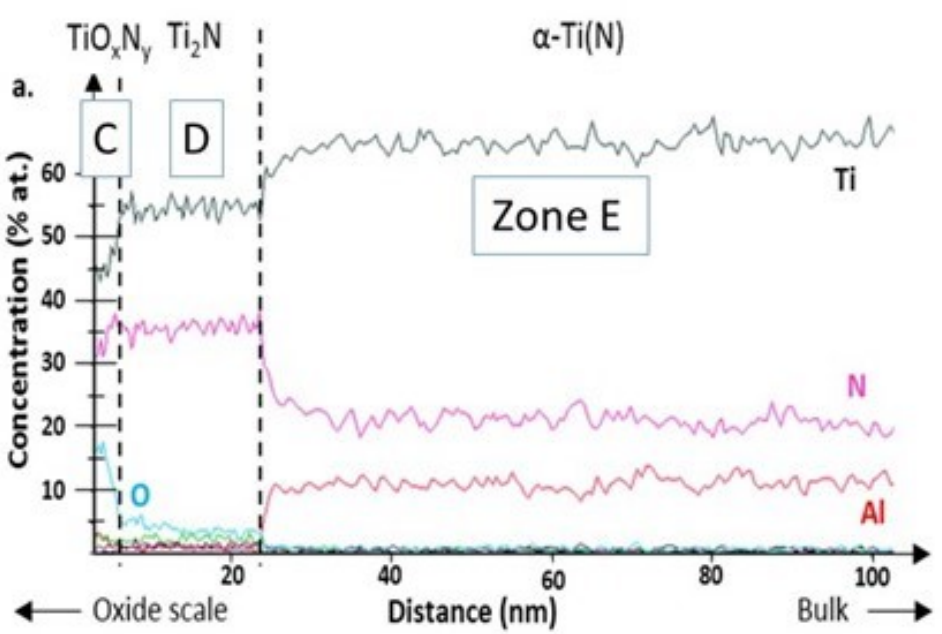

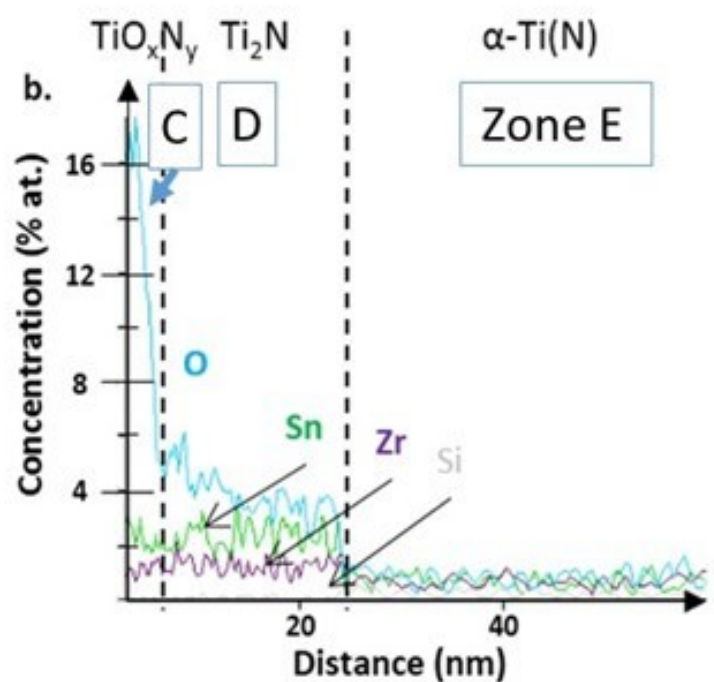

Figure 7: Concentration profiles in one micro-tip analysed by APT after oxidation at $650{ }^{\circ} \mathrm{C}$ for $1000 \mathrm{~h}$ in synthetic air a. global and b. enlargement for the 60 first nanometres

From the comparison of the previous results (Figure 6 and Figure 7), it appears that a high concentration of 29 at.\% in oxygen is found in the $\mathrm{a}-\mathrm{Ti}(\mathrm{O})$ phase just below the oxide scale, for the Ti6242S oxidized in $\mathrm{Ar}-20 \% \mathrm{O}_{2}$ i.e. without nitrogen. This value is closed to the solubility limit of oxygen in a-Ti. On the contrary, a titanium nitride $\mathrm{Ti}_{2} \mathrm{~N}$ and a solid solution enriched in nitrogen formed during oxidation in synthetic air. These two phases contained low amounts of oxygen: 3-4 at.\% for $\mathrm{Ti}_{2} \mathrm{~N}$ and less than 1 at.\% for $\mathrm{a}-\mathrm{Ti}(\mathrm{N})$. Then, it is shown than titanium nitride $\mathrm{Ti}_{2} \mathrm{~N}$ and $\mathrm{a}-\mathrm{Ti}(\mathrm{N})$ could both act as a diffusion barrier for oxygen. This finding can explain the decrease of oxygen dissolution within the alloy when oxidized in a nitrogen-rich atmosphere.

Among the three micro-tips prepared after oxidation in synthetic air, one presented a zone rich in Ti and Mo (Figure 8 and Figure 9). It could be the $\beta$-Ti phase, as molybdenum is known to segregate preferentially in this phase compared to the $\alpha$-Ti phase. Besides, no Mo (less than 0.1 at.\%) was detected in the $\alpha$-Ti phase in the five other micro-tips. On both sides of the $\beta$-Ti, a phase enriched in titanium and nitrogen formed, corresponding to the titanium nitride $\mathrm{Ti}_{2} \mathrm{~N}$ as already observed in the micro-tip related to synthetic air (Figure 7). The presence of this nitride was confirmed by the element partitioning. Indeed, if the phase around the $\beta$-Ti phase was $a-\mathrm{Ti}$, Sn and $\mathrm{Zr}$ would be found equally in both phases and $\mathrm{Al}$ and $\mathrm{O}$ would be strongly segregated in $\alpha-\mathrm{Ti}$. However, it was seen from this micro-tip that these four elements were all preferentially segregated in the $\beta$-Ti phase. Therefore, it was most likely that the phase surrounding $\beta$-Ti corresponded to the titanium nitride $\mathrm{Ti}_{2} \mathrm{~N}$. It is worth noting that our analyses showed that oxygen solubility is higher in $\beta-\mathrm{Ti}$ than in $\mathrm{Ti}_{2} \mathrm{~N}$. A fourth zone that contained about 20 at.\% of $\mathrm{N}$ and 11 at.\% of $\mathrm{Al}$ was observed deeper in the alloy. Knowing that nitrogen solubility in pure titanium is 23 at.\% and that aluminium content in the alloy is 10 at.\%, this area was identified as a solid solution of Ti and N. However, it has to be mentioned that the interface between $\mathrm{Ti}_{2} \mathrm{~N}$ titanium nitride and this solid solution was not obvious. 3D maps showed that each zone, identified as $\mathrm{Ti}_{2} \mathrm{~N}$ and $\mathrm{a}-\mathrm{Ti}(\mathrm{N})$, were single phased as only local changes in composition were observed.

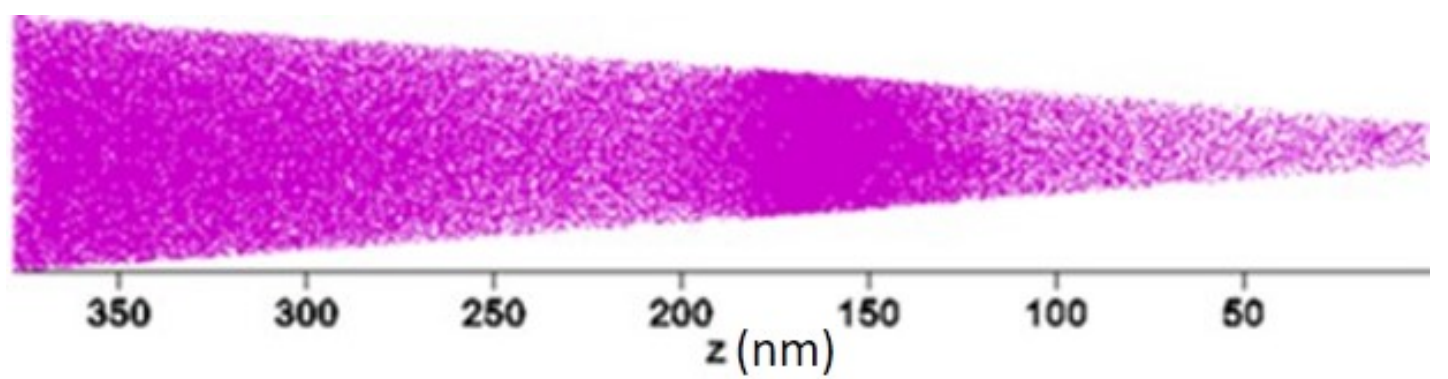

Figure 8: Elemental mapping of molybdenum obtained from the micro-tip analysed by APT and containing the $\beta$-phase after oxidation at $650{ }^{\circ} \mathrm{C}$ for 1000 $h$ in synthetic air 


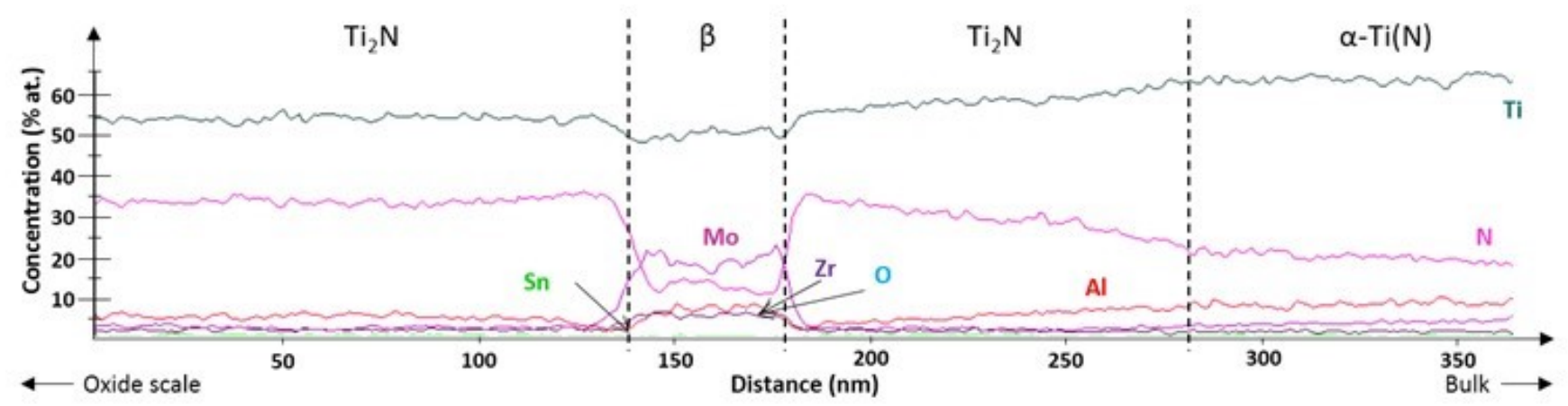

Figure 9: Concentration profiles in the micro-tip analysed by APT and containing the $\beta$-phase after oxidation at $650{ }^{\circ} \mathrm{C}$ for $1000 \mathrm{~h}$ in synthetic air

\section{Conclusions}

The effect of nitrogen on the oxidation behaviour of Ti-6Al-2Sn-4Zr-2Mo-0.1Si titanium-based alloy was studied at $650{ }^{\circ} \mathrm{C}$ for $1000 \mathrm{~h}$ in synthetic air $\left(\mathrm{N}_{2}-20 \% \mathrm{O}_{2}\right)$ and in a mixture of $\mathrm{Ar}-20 \% \mathrm{O}_{2}$. Results showed that nitrogen decreases the oxidation kinetics by decreasing the oxide scale growth as well as the oxygen dissolution within the alloy. According to APT analyses, this is due to the formation of $\mathrm{Ti}_{2} \mathrm{~N}$ titanium nitrides and of a nitrogen-rich titanium-based solid solution, which both act as diffusion barriers. For oxidation in $\mathrm{Ar}-20 \% \mathrm{O}_{2}$, TiO titanium oxide and the solid solution $a-T i$ enriched in oxygen were identified. These phase identifications are summarized on Figure 10.
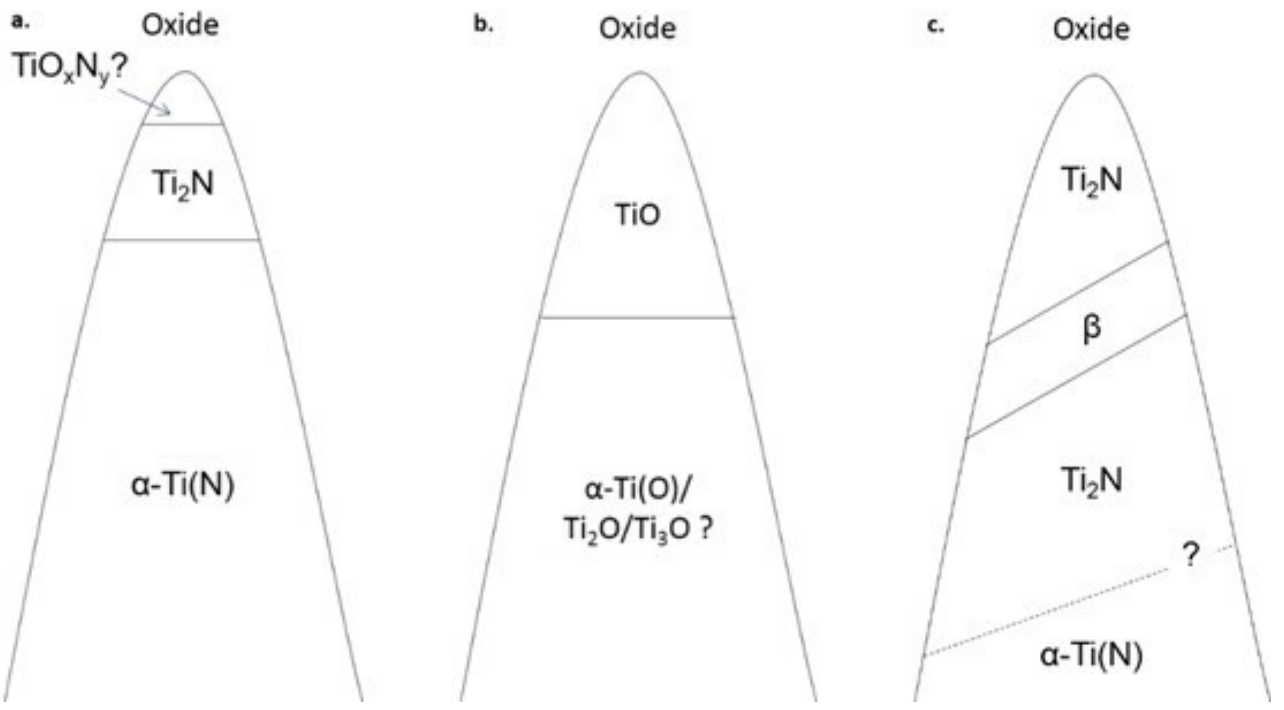

Figure 10 : Schema of micro-tips analysed by APT after oxidation at $650^{\circ} \mathrm{C}$ for $1000 \mathrm{~h}$ a. in synthetic air, b. in Ar- $20 \% \mathrm{O}_{2}$ and c. in synthetic air with $\beta$-Ti

\section{Acknoledgments}

This work was supported by the French National Research Agency through the project ANR DUSTI in partnership between Airbus, Airbus Group Innovations, Aubert and Duval, Liebherr Toulouse Aerospace, Institut Pprime, Institut Jean Lamour and CIRIMAT Laboratory.

\section{References}

[1] Finlay WL, Snyder JA. J. of Met. 188 (1950) 227-86.

[2] Fukai H, Iizumi H, Minakawa K, Ouchi C., Isij International. 45(1) (2005) 133-41.

[3] Satko DP, Shaffer JB, Tiley JS, Semiatin SL, Pilchak AL, Kalidindi SR, et al. Acta Mater. 107 (2016) 377-89.

[4] Chaze AM, Coddet C., J. of the Less Common Met. 124 (1986) 73-84.

[5] Dupressoire C, Rouaix-Vande Put A, Emile P, Archambeau-Mirguet C, Peraldi R, Monceau D., Oxid. of Met. 87 3-4 (2017) $343-53$. 
[6] Raffy M. Etude de l'oxydation de l'alliage eutectique Ti-Si à $8,5 \%$ en poids de $\mathrm{Si}$ aux températures inférieures à $850^{\circ} \mathrm{C}$. Influence de l'état structural Thesis Ecole Nationale supérieure de Chimie de Paris; 1981.

[7] Strafford KN., Corr. Sc. 19(1) (1979) 49-62.

[8] Chaze AM, Coddet C., J. of Mater. Sc. 22(4) (1987) 1206-14.

[9] Chaze AM, Coddet C., Oxid. of Met. 21 (3-4) (1984) 205-31.

[10] Chaze AM, Coddet C., Oxid. of Met. 27(1-2) (1987) 1-20.

[11] Rakowski J, Monceau D, Pettit FS, Meier GH, Perkins RA, editors. Microscopy of Oxidation 2; Selwyn College, U. of Cambridge: The Institute of Materials (1993).

[12] Becker S, Rahmel A, Schorr M, Schütze M., Oxid. of Met. 38(5) (1992) 425-64.

[13] Kanjer A., Optasanu V., Marco de Lucas MC., Heintz O., Geoffroy N., François M,. Berger P., Montesin T., Lavisse L., Surf. \& Coat. Tech. 343 (2018) 93-100.

[14] Yan M, Dargusch MS, Ebel T, Qian M., Acta Mater. 68 (2014) 196-206.

[15] Tan X, Kok Y, Toh WQ, Tan YJ, Descoins M, Mangelinck D, Tor S. B., Leong, K. F., Chua C.K., Nature 6 (2016) 1-10.

[16] Rugg D, Britton TB, Gong J, Wilkinson AJ, Bagot PAJ., Mater. Sc. Eng. A. 599(Supplement C) (2014) 166-73.

[17] Thompson K, Lawrence D, Larson DJ, Olson JD, Kelly TF, Gorman B., Ultramicroscopy. 107(2) (2007) 131-9.

[18] Larson, D.J., et al., Ultramicroscopy, 79(1) (1999) 287-293.

[19] B. Gault, M.P. Moody, J.M. Cairney, S.P. Ringer, Atom Probe Microscopy, Springer Science \& Business Media, 2012.

[20] Schuster, J.C. and J. Bauer, J. of Solid State Chem. 53(2) (1984) 260-265.

[21] Wriedt, H.A. and J.L. Murray, Bull. of Alloy Phase Diagrams. 8(4) (1987) 378-388. 